\title{
Time Affordances and Physical Mobility in the Context of Ubiquitous Technologies
}

\author{
Larissa Pschetz \\ University of Dundee, Perth Road, Dundee, DD1 4HT, UK \\ Edinburgh College of Art, Lauriston Place, Edinburgh, EH3 9DF, UK \\ pschetz@dundee.ac.uk, pschetz@eca.ac.uk
}

\begin{abstract}
This research aims to use design demonstrators to speculatively explore the relation between perceived time affordances and physical mobility in the context of ubiquitous technologies.
\end{abstract}

Keywords: user experience based approaches, speculative design,

\section{Introduction}

Recent interconnections of physical movement and communication systems are increasingly detaching geographic locations from underlying concepts of distance and co-presence [5]. As handheld devices allow a large number of activities to be performed on the go, individuals are encouraged to undertake longer hours of travel, and distance becomes ever more irrelevant. As a result, networks start to be structured more around individuals than around places, homes and contexts [6]. Daily schedules can be negotiated dynamically and become increasingly desynchronised from work, community and place, and hence from each other [15]. Technological developments not only contribute to free networks from geographical boundaries, but also set less utilitarian roles for spatial cognition [4] - as GPS-devices specifically and general automated travel technology enable people to navigate in completely unfamiliar settings with no prior planning [14].

Mobility thus is less constrained by geographic distances and is increasingly detached from spatial cues. It is however still and increasingly bound to individuals' schedules and personal relation to time [6]. Though there has been a lively debate among social scientists [17] on possible new notions of time provided by new technologies, there has been little research on relations between time perception and human mobility, and even less on the practical consequences of such notions for the design of new technologies. In HCI, supporting physical mobility is mostly associated to improving mobile infrastructure (e.g. accessibility [12], privacy [16] and services [13]), or to facilitating wayfinding e.g. [10]. While the first focuses on setting up the context of ubiquitous computing, the second approaches only one immediate aspect of physical mobility. As asserted by sociologist John Urry [1], demand for travel and movement tend to be treated as "either self-explanatory or exogenous to the system". Therefore, the present research intends to extend the current HCI discussion by 
considering physical mobility within a broader context. In particular, it will investigate the social ecologies around time perception and how it influences individual movements.

\section{Research Hypothesis}

The main hypothesis of this research is that physical mobility patterns in ubiquitous technological contexts are more strongly influenced by perceived time affordances than by geographic constraints. The idea is that, in highly technological contexts, individuals' movements are triggered, delayed and paced, not by notions of geographic distances nor by difficulties in localising routes, but by the perception that a schedule can be negotiated, meeting times can be squeezed, or that a place can be reached within a certain period of time. Technologies provoke multidimensional practices of time and new meanings of temporality [8], which consequently influence movement.

The challenge of this research is to harness technology that not only recognises, but celebrates the fact that perceived time affordances can vary greatly according to different social backgrounds and access to different technologies.

\section{Methodology}

The chosen methodology can be divided in four different phases as follows:

1) Development of demonstrators. Based on literature review and ethnographybased methods [11], major influences of current technological devices on physical mobility have been initially identified. By emphasizing time as the main driver for physical movement, mobility was then speculatively projected [9] into different scenarios, which did not intend to fit or present an accurate account of reality. Instead, it attempted to exaggerate critical aspects of pre-defined subjects in order to stimulate discussion. Such speculations were then translated into concrete products [18] that embodied these critical aspects in order to let participants experience alternative situations and later discuss their experiences. The design process consisted in exploratory and playful experimentations [7] with different kinds of hardware and information technology services, in which methods such as experience prototyping [3] and the already cited scenarios [2] were included. I will now present two examples of demonstrators developed in the context of this research.

a) The Family Clock speculates on the increasingly temporal flexibility provided by handheld devices. A family shares a clock whose rhythm is set collectively by its members according to their individual pace of life. The physical clock is placed in a common room, while its time is sped up or delayed throughout the day via family members' mobile phones until it reaches equilibrium. The clock allows families to choose their own temporal state, which can be slightly slower or faster than universal time.

b) The Transportation Clocks address issues of distance and social attachment. A pair of clocks constantly displays the time necessary to reach each other based on pubic transportation schedules. Serving as a dynamic souvenir of the person, its aim is 
not to fulfil utilitarian purposes, but to present a more personal way of perceiving time and distance, which in turn is expected to prompt discussion on the way these dimensions are generally perceived.

2) Experience evaluation. The developed design demonstrators will be presented to groups of users in order to discuss the relevance of each embodied subject. Though the circumstances of such assessment vary according to each demonstrator, participants will be asked to carry the artefacts or keep them at their homes for extended periods of time. During this period they will be asked to keep a written, visual or spoken diary of their impressions. Prompts developed based on ethnographic practices [11] will be provided to support the records. These practical experiments will be followed by focus groups or semi-structured interviews, which will allow us to understand the rationale behind methods adopted to record impressions, as well as formal features, potential for raising discussion, and the relevance of issues embodied by each designed artefact.

3) Refinements. It is expected that the evaluation phase will provide insights for refinements or for the development of new demonstrators, in an attempt to increase the complexity of proposed subjects. These refinements, in turn, will lead to new evaluations, in an iterative process.

4) Guidelines definition. Based on the insights gained at the evaluation phase, a set of guidelines will be defined to allow future researchers to either reproduce or apply the knowledge generated in the process.

\section{Expected Contributions}

This research will provide design-led evidence to support speculations on the future of physical mobility. By looking beyond the solving of problems related to mobility, towards an approach that explores the opportunities presented by existing and emerging technologies, the research expects to expand the scope of current $\mathrm{HCI}$ analysis on spatial mobility, generating new knowledge for mobility technology through: a) discursive accounts of user experiences of artefacts that play with perceptions of time and movement, $b$ ) a design based lens for looking deeply at mobility opportunities, $c$ ) a series of prototypes and artefacts that demonstrate and enable discussion on these opportunities, $d$ ) a set of design guidelines for implementing a future that has a rich and ubiquitous use of mobility technology.

Acknowledgement. This work was supported by Microsoft Research through its PhD Scholarship Programme.

\section{References}

1. Adey, P., Bissell, D.: Mobilities, meetings, and futures: an interview with John Urry. Environment and Planning D: Society and Space 28(1), 1-16 (2010)

2. Bødker, S.: Scenarios in user-centred design: setting the stage for reflection and action. Interacting with Computers 13(1), 61-75 (2000) 
3. Buchenau, M., Suri, J.F.: Experience prototyping. In: Proceedings of the 3rd Conference on Designing Interactive Systems. ACM, New York (2000)

4. Burnettand, G.E., Lee, K.: The effect of vehicle navigation systems on the formation of cognitive maps. In: International Conference of Traffic and Transport Psychology (2005)

5. Cresswell, T.: On the Move, 1st edn. Routledge, New York (2006)

6. Elliott, A., Urry, J.: Mobile Lives, 1st edn. Routledge, New York (2010)

7. Gaver, B., Martin, H.: Alternatives: exploring information appliances through conceptual design proposals. In: Proceedings of the SIGCHI Conference on Human Factors in Computing Systems, CHI 2000, pp. 209-216. ACM, New York (2000)

8. Hörning, K.H., Ahrens, D., Gerhard, A.: Do technologies have time? Time \& Society 8(23), 293-308 (1999)

9. Kerridge, T.: Does speculative design contribute to public engagement of science and technology? In: Proceedings of Multiple Ways to Design Research (2009)

10. Leshed, G., Velden, T., Rieger, O., Kot, B., Sengers, P.: In-car gps navigation: engagement with and disengagement from the environment. In: SIGCHI Conference on Human Factors in Computing Systems, CHI 2008. ACM, New York (2008)

11. MacAulay, C.: Ethnography, theory and systems design: from intuition to insight. International Journal of Human-Computer Studies 53(1), 35-60 (2000)

12. Nilsson, V.: Ability by mobility. In: CHI 2001 Extended Abstracts on Human Factors in Computing Systems, CHI EA 2001. ACM, New York (2001)

13. O’Hara, K., Black, A., Lipson, M.: Everyday practices with mobile video telephony. In: Proceedings of the SIGCHI Conference on Human Factors in Computing Systems, CHI 2006, pp. 871-880. ACM, New York (2006)

14. Rajamani, R.: Vehicle Dynamics and Control, 1st edn. Springer, Heidelberg (2005)

15. Southerton, D., Shove, E., Warde, A.: Harried and hurried: time shortage and the coordination of everyday life. CRIC Discussion Paper, 47 (2002)

16. Tarasewich, P., Gong, J., Conlan, R.: Protecting private data in public. In: CHI 2006 Extended Abstracts on Human Factors in Computing Systems, CHI EA 2006, pp. 14091414. ACM, New York (2006)

17. Wajcman, J.: Life in the fast lane? towards a sociology of technology and time. The British Journal of Sociology 59(1), 59-77 (2008)

18. Zimmerman, J., Stolterman, E., Forlizzi, J.: An analysis and critique of research through design: towards a formalization of a research approach. In: Proceedings of the 8th ACM Conference on Designing Interactive Systems, DIS 2010, pp. 310-319. ACM, New York (2010) 